DOI: http://dx.doi.org/10.19177/reen.v14e1202195-119

\title{
PERCEPÇÕES DE COMITÊS SOBRE A APLICAÇÃO DA GOVERNANÇA PÚBLICA FEDERAL
}

\section{PERCEPTIONS OF COMMITTEES ON THE APPLICATION OF FEDERAL PUBLIC GOVERNANCE}

\section{PERCEPCIONES DE COMITÉS SOBRE LA APLICACIÓN DE LA GOBERNANZA PÚBLICA FEDERAL}

\section{Karoll Haussler Carneiro Ramos}

Doutora em Engenharia Elétrica pela Universidade de Brasília (UnB)

Professora do Instituto Brasileiro de Governança Pública (IBGP) e do Departamento de Administração da Universidade de Brasília (UnB)

E-mail: karoll.ramos@gmail.com

\section{Lana Montezano}

Doutora em Administração (Gestão de Pessoas e Inovação) pela Universidade de Brasília (UnB)

E-mail: lanaconsult@gmail.com

\section{Andressa Oliveira Pinheiro}

Graduação em Administração e em Ciências Contábeis pela Universidade de Brasília (UnB)

Professora e Pesquisadora na UnB

E-mail: andressa.opinheiro@gmail.com

\section{Marcos da Costa Avelar}

Especialista em Especialização em Orçamento e Políticas Públicas pela Universidade de Brasília (UnB) Analista de Planejamento e Orçamento do Ministério da Economia

E-mail: marcos.avelar@economia.gov.br

Artigo recebido em 07/01/2019. Revisado por pares em 12/04/2021. Reformulado em 15/04/2021. Recomendado para publicação em 20/04/2021, por Ademar Dutra (Editor Científico). Publicado em 30/04/2021. Avaliado pelo Sistema double blind review.

(c) Copyright 2021 UNISUL-PPGA/Revista Eletrônica de Estratégia \& Negócios. Todos os direitos reservados. Permitida citação parcial, desde que identificada a fonte. Proibida a reprodução total.

Revisão gramatical, ortográfica e ABNT de responsabilidade dos autores. 


\section{RESUMO}

Este artigo descreve a percepção dos comitês de uma organização pública federal brasileira sobre implantação da governança pública, sob a perspectiva do seu entendimento conceitual e de possíveis dificuldades e ganhos. Para tanto, aplicou-se um questionário com os membros dos Comitês Estratégico e Tático Operacional, constatando-se que esses estão alinhados à definição de governança estabelecida na legislação vigente. Sobre as dificuldades, destacamse limitações em aspectos culturais do serviço público e em processo de comunicação. Os possíveis ganhos apontam para melhorias de gestão de um modo geral, de processos e de riscos; melhorias no alcance de resultados; e maior transparência.

Palavras-chaves: Governança pública; Administração pública; Triangulação de pesquisadores; Análise de conteúdo.

\section{ABSTRACT}

This article describes the committees' perception of a Brazilian federal public organization on the implementation of Public Governance, from the perspective of its conceptual understanding and possible difficulties and gains. Therefore, we have applied a questionnaire with members of the Strategic and Tactical Operational Committees, and they are aligned with the definition of governance established in the current legislation. About difficulties, there are limitations in cultural aspects of public service and in communication process. The potential gains indicate improvements in management in a general way; processes and risks; improvements in achieving results; and greater transparency.

Keywords: Public governance; Public administration; Triangulation of researchers; Content analysis.

\section{RESUMEN}

Este artículo describe la percepción de comités de una organización pública federal brasileña sobre implantación de la Gobernanza Pública, desde la perspectiva de su entendimiento conceptual, posibles dificultades y beneficios. Así, se ha aplicado un cuestionario con los mienbros de los Comités de Estrategia y Tácticos Operacionales, mostrándolos alineados a la definición de gobernanza establecida en la legislación vigente. Las dificultades se referen a limitaciones en aspectos culturales del servicio público y proceso de comunicación insuficiente. Los posibles benefícios descubiertos son mejoras de gestión en general, de procesos, de riesgos y en el alcance de los resultados y mayor transparência.

Palabras clave: Gobernanza pública; Administración pública; Triangulación de investigadores; Análisis de contenido. 
PERCEPÇÕES DE COMITÊS SOBRE A APLICAÇÃO DA GOVERNANÇA PÚBLICA FEDERAL Karoll Haussler Carneiro Ramos - Lana Montezano - Andressa Oliveira Pinheiro - Marcos da Costa Avelar

\section{INTRODUÇÃo}

Nas últimas décadas a administração pública busca novos modelos organizacionais a fim de garantir mais eficiência e eficácia na gestão, reduzindo a "burocracia" e o déficit público (FLÓREZ, 2017). Nessa perspectiva, abrem-se margens para a interpretação e desejo de um cenário político menos assimétrico, com maior divulgação de informações, para que a sociedade possa exercer a democracia de forma completa, auxiliando na verificação e controle das ações realizadas por seus representantes.

O fortalecimento da gestão pública nos últimos 20 a 30 anos motivada por iniciativas, como movimento New Public Management e as reformas financeiras, contribuíram para a boa governança pública (BARRETT, 2014). Especificamente o New Public Management ganhou influência mundial na década de 1990, quando orientou a gestão pública para a oferta de bons serviços à população embasados em responsabilidade, em boas práticas (FLÓREZ, 2017), em transparência e em descentralização do setor público (MATIAS-PEREIRA, 2010). Nesse sentido, a reforma gerencial introduziu atualmente o zelo por informações tempestivas, objetivas, claras e transparentes. Sob esse aspecto da disponibilização de informações, a boa experiência das modernas práticas de gestão no setor privado motivou a adaptação e a transferência de experiências para o setor público, sendo um dos pilares para governança pública.

Insta frisar que além desses desafios centrados na eficiência, na efetividade, na prestação de contas, na transparência e na legalidade, tem-se abordagem com foco na participação social, visando a entrega de serviços públicos de qualidade, bem como o controle social (BUTA; TEIXEIRA, 2020).

A governança para o setor público foi impulsionada pelo Tribunal de Contas da União (TCU) e por diversos normativos, como: i) Código de Ética Profissional do Servidor Público Civil do Poder Executivo Federal (Decreto n. 1.171/1998); ii) Lei das Contas Públicas (Lei n. 9.755/1998); iii) Lei de Responsabilidade Fiscal (Lei Complementar n. 101/2000); iv) Decreto de Gestão da Ética (Decreto n. 6.029/2007); v) Decreto de Vedação ao Nepotismo (Decreto n. 7.203/2010); vi) Lei de Acesso à Informação (Lei n. 12.527/2011); vii) Lei de Conflito de Interesses (Lei n. 12.813/ 2013); viii) Lei das Estatais (Lei n. 13.303/2016); ix) Decreto da 
Política de Governança da administração pública federal direta, autárquica e fundacional e Governança Pública (Decreto n. 9.203/2017). (BRASIL, 2020).

Nesse contexto e para esta pesquisa, a administração pública federal centra a prática de sua governança na prestação de contas e conformidade legal, seguindo as diretrizes dos órgãos de controle externo. Todavia, o sentido de governança corporativa no setor público ou governança pública organizacional que trata esta pesquisa são:

Os mecanismos de liderança, estratégia e controle postos em prática para avaliar, direcionar e monitorar a atuação da gestão, com vistas à condução de políticas públicas e à prestação de serviços de interesse da sociedade (BRASIL, 2020, p.36).

A importância da governança corporativa no setor público é que essa viabiliza empreendimentos públicos com potencial de enfrentar problemas presentes e futuros, podendo ser compreendida como o sistema de proteção dos interesses dos cidadãos contra os atos danosos que os agentes públicos podem provocar ao patrimônio público (PROCOPIUK, 2013).

No aspecto acadêmico, alguns estudos (BENEDICTO et al., 2013; CAMPANÁRIO et al., 2014; FLÓREZ et al., 2017; PEIXE, ROSA FILHO; PASSOS, 2018) reforçam a necessidade de realizar-se pesquisas sobre a aplicabilidade e as contribuições da governança em organizações públicas.

Alguns autores constataram crescente número de pesquisas sobre a governança no Brasil, existindo maior concentração em organizações privadas, além de identificarem escassez de estudos que abordassem benefícios e barreiras sobre a temática, o que aponta uma lacuna de estudos em organizações públicas (DUARTE, CARDOZO; VICENTE, 2012; WEBER, DOS SANTOS, 2020). Adiciona-se a Operação Lava-Jato, deflagrada em março de 2014 e a edição da Lei das Estatais (Lei n. 13.303/2016), objetivando o combate à corrupção e fraudes por meio da adoção de políticas de compliance e governança corporativa (PEREIRA; FARIA, 2017; GOUVÊA, 2020).

Dado este contexto e considerando a relevância do tema governança no setor público, o presente artigo tem como objetivo descrever a percepção dos servidores públicos que compõe os Comitês Estratégico e Tático Operacional de uma organização pública federal 
PERCEPÇÕES DE COMITÊS SOBRE A APLICAÇÃO DA GOVERNANÇA PÚBLICA FEDERAL Karoll Haussler Carneiro Ramos - Lana Montezano - Andressa Oliveira Pinheiro - Marcos da Costa Avelar

brasileira sobre implantação da governança. Para atender ao proposto, deu-se enfoque no seu entendimento conceitual, bem como nas dificuldades e nos possíveis ganhos de sua implantação em uma Secretaria da Administração Direta do Governo Federal.

Após essa seção, são apresentados: referencial teórico, que trabalhará com a conceituação acadêmica da governança, bem como com temas relativos que originaram essa expressão e a ocorrência na administração pública; método de pesquisa, delineando a classificação, e o procedimento de coleta e análise dos dados; resultados, apresentando a aplicação e discussão do tema; e considerações finais com a proposta de agenda de pesquisa.

\section{REFERENCIAL TEÓRICO}

\subsection{GOVERNANÇA CORPORATIVA NO SETOR PÚBLICO}

Conforme Flórez (2017), a governança corporativa no setor público teve início na década de 1980 no Reino Unido na administração de Margaret Thatcher, e nos Estados Unidos da América no governo de Ronald Reagan, em que ambos os governos iniciaram a prática nos setores da saúde e da educação. Depois, Austrália, Nova Zelândia e Canadá, também iniciaram a implementação da governança pública por essas áreas. Especificamente sobre o setor saúde, o autor informa que essa área recebeu contribuições significativas da governança corporativa.

Dado que a prática de governança corporativa pública tem influência das modernas práticas de gestão no setor privado, por meio de princípios que são aplicáveis também ao Estado (INSTITUTO BRASILEIRO DE GOVERNANÇA CORPORATIVA, 2015) faz-se necessário, inicialmente, a compreensão desse tema no cenário corporativo, de um modo geral.

A ideia de governança surgiu a partir dos conflitos provocados pelos interesses antagônicos de proprietários (acionistas) e administradores, no qual a assimetria de informações, juntamente com o pensamento racional de maximização dos ganhos, incentivava por parte dos agentes de governança, muitas vezes na figura do conselho de administração, a tomada de decisões que vão de encontro ao ansiado pelos administradores (EISENHARDT, 2015). 
PERCEPÇÕES DE COMITÊS SOBRE A APLICAÇÃO DA GOVERNANÇA PÚBLICA FEDERAL Karoll Haussler Carneiro Ramos - Lana Montezano - Andressa Oliveira Pinheiro - Marcos da Costa Avelar

Para a Organização para a Cooperação e Desenvolvimento (OCDE), a governança é um sistema em que se esclarece a estrutura por meio da qual são fixados os objetivos organizacionais para direção, incentivo e alcance dos mesmos, além do seu monitoramento (ORGANIZAÇÃO PARA A COOPERAÇÃO E DESENVOLVIMENTO, 2004). Em complemento a esta definição, o Instituto Brasileiro de Governança Corporativa (INSTITUTO BRASILEIRO DE GOVERNANÇA CORPORATIVA, 2015), referência em assuntos dessa temática no Brasil, especifica a necessidade de envolver os relacionamentos entre as partes interessadas da organização, tais como sócios, conselho de administração, diretoria, órgãos de fiscalização e controle e demais interessados.

Tal estrutura apontada deve ser suportada por determinados princípios como transparência, prestação de contas (accountability), integridade (INTERNATIONAL FEDERATION OF ACCOUNTANTS, 2014), equidade e responsabilidade corporativa (INSTITUTO BRASILEIRO DE GOVERNANÇA CORPORATIVA, 2015). Sob esses princípios, a governança preocupa-se com os interesses dos acionistas, não excluindo os acionistas minoritários, e o desempenho organizacional. Agindo assim, essa ganha o status de boa governança (MARQUES, 2007; MATIAS-PEREIRA, 2009), na qual está incluso cuidado pelo planejamento de negócio, planejamento estratégico, comités de auditoria, controle de estruturas, gestão de risco, avaliação e monitorização do desempenho (MARQUES, 2007). Piemonte (2010, p. 264) complementa relatando que, para desenvolvê-la, é aconselhável que as organizações só comecem a implementar ações de governança "quando já existe certo nível de experiência com o tratamento de processos na organização".

Vale frisar que no tocante ao universo da literatura, as principais variáveis de governança pública apontadas por Castelo et al. (2017), estão centradas em modelos de desempenho; consistência estratégica de governança; capacidade de performance de governança; governança local; unidade de propriedade de governança; percepção clientecidadão e governança e; federalismo fiscal. Segundo Dano et al. (2018), ações de governança pública objetivam aumentar o sentimento de confiança da sociedade, melhorando indicadores sociais e econômicos pela participação efetiva da sociedade civil nos programas do governo. 
PERCEPÇÕES DE COMITÊS SOBRE A APLICAÇÃO DA GOVERNANÇA PÚBLICA FEDERAL Karoll Haussler Carneiro Ramos - Lana Montezano - Andressa Oliveira Pinheiro - Marcos da Costa Avelar

Especificamente no Brasil, a governança na Administração Pública Federal foi impulsionada pela governança de tecnologia da informação e comunicação (TIC), a partir da constatação de que o processo de compras e planejamento de TI era ineficiente, além de que os gastos anuais do governo em TIC superaram três bilhões de reais (MOLINARO; RAMOS, 2011; RAMOS, 2015).

Depois do foco em TIC, o TCU emitiu um Referencial Básico de Governança a ser aplicado por todos os órgãos e entidades da Administração Pública, como forma de contribuir com diretrizes para adoção da Governança Pública (BRASIL, 2014). A fim de assegurar que os princípios da governança sejam observados no Brasil, as seguintes legislações devem ser cumpridas: Constituição Federal de 1988, Decreto n. 1.171/94, Lei Complementar n. 101/2000, Lei n. 12.813/2013, Lei n. 12.527/2011 (TRIBUNAL DE CONTAS DA UNIÃO, 2014). Além desses, recentemente entrou em vigor o Decreto n. 9.203/2017 (BRASIL, 2017) que “dispõe sobre a política de governança da administração pública federal direta, autárquica e fundacional", apontando o conceito de governança pública como o "conjunto de mecanismos de liderança, estratégia e controle postos em prática para avaliar, direcionar e monitorar a gestão, com vistas à condução de políticas públicas e à prestação de serviços de interesse da sociedade".

Assim, considerando o objetivo desta pesquisa, o conceito de governança pública a ser adotado é o exposto em Brasil (2014), no qual a governança pública é um instrumento de direção, monitoramento e avaliação de estruturas administrativas, como cultura organizacional e processos), sociedade e outras partes interessadas ao processo e de responsabilidades, com objetivo de prover sistemas políticos e administrativos de efetividade em suas ações.

\subsection{FATORES QUE CONTRIBUEM PARA A BOA GOVERNANÇA PÚBLICA}

Conforme o International Federation of Accountants (IFAC) (2014), a finalidade da boa governança no setor público é garantir que as suas organizações atuem sempre conforme o interesse público. O IFAC (2014) entende que governança compreende a estrutura posta em prática para garantir que os resultados pretendidos pelas partes interessadas sejam definidos e alcançados e, além disso, tenha conselhos representantes da sociedade civil, planejamento 
organizacional; comitês internos; excelência de pessoal e descentralização administrativa; gestão de riscos; publicação de planos, portfólios e resultados, avaliações de desempenho individual e organizacional; auditoria interna; e controle externo.

Conforme Branco e Cruz (2013), esses e outros mecanismos são úteis para aumentar o valor obtido da aplicação dos recursos, conferir maior transparência, assegurar a conformidade com as normas, mitigar riscos de não alcance de metas e melhorar a prestação de serviços à sociedade. A percepção de confiança da sociedade em relação aos serviços públicos é obtida pelo provimento de bens e serviços que elevem o bem-estar social, sendo que quanto maior a qualidade da governança pública, maior será a confiança do cidadão (DANI et al., 2018). Entretanto, vale frisar que segundo Brocco et al. (2018), quando se fala na participação da sociedade na governança pública, são os cidadãos com melhores condições de saúde, de educação e com empregabilidade que possuem condições de exercer o controle social.

Costa et al. (2018) constataram que a adoção da gestão de processos é um meio para viabilizar a efetiva governança em organização pública, e que se alinhada às diretrizes estabelecidas pelo TCU (BRASIL, 2020), é possível obter maior transparência e eficiência das atividades realizadas, facilitar o cumprimento dos resultados, maior envolvimento dos servidores das diferentes áreas, além de permitir a identificação de competências dos envolvidos no processo e de possíveis falhas.

Para Barrett (2014), a governança pública deve adquirir o status de "boa", indicando que além de cumprir com os princípios supracitados, a liderança da instituição, o seu pessoal, o governo e a população contam que a organização pública faça bem o seu trabalho com probidade e com accountability.

O sentido "boa governança pública" enfatiza o desempenho (BARRETT, 2014; WATERMAN, 2014; BEERI, USTER, VIGODA-GAGOT, 2018). O desempenho faz com que organização utilize seu sistema de governo, contribuindo para o desempenho global e para as entregas de valor, bens, serviços ou programas à sociedade. No aspecto da conformidade, a organização pública deve utilizar seus arranjos de governança, garantido o cumprimento dos 
requisitos da lei, regulamentos, normas publicadas e reconhecidas expectativas de probidade, responsabilidade e abertura.

Accountability ou responsabilização, também é um aspecto da "boa governança" que no setor público serve aos propósitos de controlar o abuso e o uso indevido da autoridade pública; de prover segurança do uso dos recursos públicos conforme estabelecido por lei e; de promover o crescimento contínuo da governança e gestão pública (WATERMAN, 2014). Além disso, recomenda-se que responsabilização não seja afetada quando o processo de governança estiver passando por mudanças.

De acordo com Barrett (2014), os modelos úteis aplicados na Austrália, país com alto grau de respeito em governança nos fóruns internacionais, indica que deve haver o estabelecimento de elos entre as reformas financeiras, accountability e o desempenho de todos os programas de governo e demais atividades. Para o autor, o foco é principalmente na reforma financeira como parte da boa governança, enfatizando o desempenho e a responsabilidade, mas também dando destaque à gestão de risco e à mais autonomia com menos burocracia. Além disso, é dada importância ao estabelecimento de uma estrutura de governança que reconheça a crescente cooperação e colaboração entre agências e entidades, governos em todos os níveis e setores da economia.

De acordo com Marques (2007), os fatores fundamentais para uma boa governança corporativa pública são a gestão da estrutura administrativa; do ambiente administrativo, da administração de risco; da conformidade e complacência; do monitoramento e avaliação de desempenho; da responsabilidade em prestar contas; e da conformidade versus desempenho. Fontes Filho (2003) também associa às questões de governança, o aspecto macro, como a gestão das políticas públicas, o exercício de poder e o controle na sua aplicação.

De acordo com Ramos (2015), os fatores críticos de sucesso em governança pública, quando observados seus princípios, designam nas seguintes atribuições: auditorias; código de conduta; relacionamento com grupos de interessados; perfil do conselho; comitês; gestão da mudança; gestão de riscos; gestão da informação; ouvidoria; planejamento e monitoramento do desempenho. 
PERCEPÇÕES DE COMITÊS SOBRE A APLICAÇÃO DA GOVERNANÇA PÚBLICA FEDERAL Karoll Haussler Carneiro Ramos - Lana Montezano - Andressa Oliveira Pinheiro - Marcos da Costa Avelar

Apesar dessas considerações, Bessa (2013, p. 11) destaca que "ainda faltam modelos aplicáveis e apropriados para se alcançar a boa governança, de forma democrática". Benedicto et al. (2013) afirmam que é possível introduzir as boas práticas de governança corporativa na gestão pública brasileira, e que a mesma vem sendo realizada de modo gradativo no estabelecimento de novos parâmetros de gestão, apesar de ainda terem aspectos culturais que precisam ser superados para efetiva adoção dos princípios de governança.

\subsection{FATORES QUE DIFICULTAM A IMPLEMENTAÇÃO DA BOA GOVERNANÇA}

Foram identificados casos na literatura da implantação da governança pública, em que Magalhães e Coelho (2018) elencaram dificuldades para adoção de mecanismos sociopolíticos de participação social, cenário político desfavorável à implantação da reforma, bem como dificuldades de cooperação interinstitucional.

Campanário et al. (2014) realizaram estudo para verificar a possibilidade de implantação da governança corporativa em empresas públicas e identificaram algumas dificuldades, tais como: legislação, interesse público, burocracia, complexidade, conjuntura eleitoral, rotatividade no cargo, discordância interna sobre princípios de governança, composição do conselho de administração, interesses políticos. Em seguida, propuseram algumas ações necessárias para adaptação do modelo ao contexto público: adaptação normativa à legislação pública, avaliar a relação entre regulamentação obrigatória em relação às necessidades de melhoria, alinhar cronogramas de início dos projetos de governança com os mandatos governamentais, ter clareza nos objetivos a serem alcançados, profissionalização do conselho de administração e realizar medidas de blindagem político-partidárias.

Kovač et al. (2016) também alertam que para gestores públicos a boa governança é considerada mais um cumprimento dos requisitos formais, em vez foco no benefício público. Além disso, os autores defendem que futuras reformas na administração pública sejam mudanças baseadas em valor e não puramente estruturais e normativas.

\subsection{ESTRUTURAS DA GOVERNANÇA CORPORATIVA NO SETOR PÚBLICO}

Flórez (2017) afirma que a estrutura da governança corporativa no setor público incorpora mais processos gerenciais na gestão da organização e reduz o número de conselhos 
nos órgãos de administração. Entretanto, sua estrutura é menos eficiente do que no setor privado.

Ao comparar as estruturas típicas de governança nos diferentes setores, verifica-se que enquanto o setor privado busca eliminar possíveis conflitos de interesse, como evitando a participação de administradores ou dos executivos principais nos quadros de governança, o setor público faz o contrário, incluindo-os na sua estrutura (MARQUES, 2007).

Graaf e Paanakker (2015) indicam que a motivação de administradores seniores do setor público ao longo da carreira é executar o sistema sem problemas, em vez de alcançar políticas ou objetivos específicos, já que, no final, são os ministros os responsáveis pelas decisões. Essas decisões não são apenas sobre os objetivos "certos" e as políticas correspondentes que devem ser tomadas, mas também as escolhas entre metas e valores de processo organizacional. Em termos de governança, os autores relatam que a questão da lealdade dos membros do conselho ao ministro é o princípio norteador que justifica suas decisões. A eficácia é geralmente entendida como "realizar os resultados que seu ministro pede", dentro de restrições de tempo, mão de obra e orçamento. Vale ressaltar que os principais administradores públicos descrevem os conflitos de valor quase exclusivamente em termos da organização da tomada de decisões, e não em termos dos efeitos (sociais) da política ou de sua implementação (GRAAF; PAANAKKER, 2015).

Considerando-se tal perspectiva e salientando-se que no caso da Administração Pública Federal Direta do Brasil, a estrutura de governança geralmente é formada pela Alta Administração, é evidente o risco de que a boa governança seja comprometida, uma vez que o princípio da segregação de papéis é falho, sendo que quem executa também é o controlador (RAMOS, 2015).

Vale salientar que para Barrett (2014), a governança pública envolve a separação das funções executivas e legislativas de governo, pois que o Parlamento (legislatura) tem autoridade para financiar a aquisição e uso de recursos de todo o setor público, sendo o governo eleito (executivo) responsável pelos recursos específicos, planejamento, direção e controle das operações deste setor. O autor explana que a legislatura tem o direito e a responsabilidade de manter o governo responsável pela gestão e atividades. Por conseguinte, 
PERCEPÇÕES DE COMITÊS SOBRE A APLICAÇÃO DA GOVERNANÇA PÚBLICA FEDERAL Karoll Haussler Carneiro Ramos - Lana Montezano - Andressa Oliveira Pinheiro - Marcos da Costa Avelar

a governança pública inclui sistemas de accountability aos ministros e ao Parlamento. 0 núcleo da missão, visão e os objetivos das agências públicas são também ajustados frequentemente a este nível (BARRETT, 2014).

\section{METODOLOGIA}

O presente artigo pode ser metodologicamente classificado da seguinte maneira: quanto ao gênero do estudo, teórico-empírico; quanto ao recorte temporal, transversal (ano de 2018); quanto ao objetivo, descritivo-exploratório; quanto à forma de abordagem, qualitativo; quanto à origem dos dados, primária.

O estudo foi realizado em uma Secretaria da Administração Direta do Governo Federal brasileiro. A estrutura de governança dessa Organização é composta pelo Comitê Gestor da Informação e pelo Comitê de Gestão, todos formados pelos membros da Alta Administração e não participaram da pesquisa. Como estrutura de apoio interno à governança, tem-se Comitê Estratégico e o Comitê Tático Operacional formados por 24 servidores do respectivo Órgão - participantes desta pesquisa.

Para a coleta dos dados, utilizaram-se questionários que foram aplicados concomitantemente ao programa de alinhamento sobre o tema Governança Pública para desenvolvimento dos membros do Comitê Estratégico e o Comitê Tático Operacional. Nesse treinamento foi abordado o seguinte conteúdo programático: governança corporativa; governança corporativa pública; princípios; estruturas; legislação; governança organizacional pública em outros países.

Estiveram presentes no treinamento 22 servidores públicos, todos lotados na Secretaria, e desempenhando os mesmos cargos de nível superior. Eles compuseram a amostra por conveniência, devido à participação voluntária em responder à pesquisa.

O instrumento para coleta dos dados se valeu de questionário aberto, dividido em quatro seções (cada seção ocorreu concomitante com os quatro módulos do treinamento). A primeira seção tratou da identificação do perfil dos respondentes (idade, sexo e tempo de serviço no Órgão), mantendo, contudo, sigilo sobre sua pessoalidade. A segunda seção abordou o conhecimento prévio (antes do treinamento) sobre o tema - experiência prática, 
PERCEPÇÕES DE COMITÊS SOBRE A APLICAÇÃO DA GOVERNANÇA PÚBLICA FEDERAL Karoll Haussler Carneiro Ramos - Lana Montezano - Andressa Oliveira Pinheiro - Marcos da Costa Avelar

treinamento anterior, ação efetiva desenvolvida pela Organização em análise (que já tenha participado dessa ação). A terceira seção, aplicada aos respondentes antes do programa de alinhamento, perguntou o que os respondentes entendiam por Governança. A quarta e última seção, aplicada após o treinamento, consistiu perguntou quais seriam as principais dificuldades e benefícios esperados com a implantação da Governança na Organização.

Para esse levantamento, solicitou-se aos participantes que respondessem a pesquisa no início das aulas, para que fosse possível coletar a compreensão do tema antes da explicação. Entretanto, não se pode assegurar que os questionários tenham sido respondidos no momento devido.

Os dados coletados foram digitados, organizados e tabulados em planilha do Excel, e analisados em duas etapas: na primeira os dados foram submetidos a três pesquisadores para realização da Análise Categorial Temática de Bardin (2011), seguindo os passos de pré- análise, exploração do material e tratamento dos resultados e interpretações. Cada pesquisador recebeu um modelo a ser preenchido com os dados coletados, para assegurar que seguiriam cada uma das etapas de Bardin (2011), como tratamento igualitário dos dados. As propostas de categorias desses pesquisadores foram consolidadas por um quarto pesquisador, de modo a analisar a convergência e possíveis divergências na análise.

O procedimento de análise dos dados constituído por quatro pessoas caracterizou como a técnica de triangulação de pesquisadores, sob diferentes óticas, a fim de aumentar a confiabilidade dos resultados obtidos (ZAPPELINI; FEUERSCHÜTTE, 2015). Tamanha é a relevância dessa técnica, que foi listada dentre as abordagens adotadas pelos principais periódicos nacionais de Administração (BROILO et al., 2015).

De modo a permitir uma compreensão geral a respeito do que os servidores entendem como governança, foi elaborada inicialmente a nuvem de palavras, com apoio do software IRAMUTEQ, para identificar as recorrências das palavras mais utilizadas. Em seguida foi realizada a consolidação e a análise dos dados obtidas na primeira etapa com os três pesquisadores. 
PERCEPÇÕES DE COMITÊS SOBRE A APLICAÇÃO DA GOVERNANÇA PÚBLICA FEDERAL Karoll Haussler Carneiro Ramos - Lana Montezano - Andressa Oliveira Pinheiro - Marcos da Costa Avelar

\section{RESULTADOS E DISCUSSÃO}

Esta seção apresenta a consolidação dos resultados quanto ao perfil dos respondentes, conhecimentos prévios sobre governança, entendimento conceitual dos participantes, principais dificuldades e benefícios esperados.

\subsection{PERFIL DOS RESPONDENTES E CONHECIMENTO PRÉVIO SOBRE O TEMA}

O Comitê estratégico é formado pelos diretores da instituição, em número de seis e o Comitê tático operacional pela média gerência, totalizando 24 ocupantes dos cargos de coordenadores-gerais.

Em relação ao perfil dos 22 respondentes, tem-se que $72,7 \%$ são do sexo masculino, a idade média é de 45,5 anos de idade (DP =6,5), com mínimo de 30 anos e máximo de 57 . A respeito do tempo de serviço na Organização, obteve-se média de 9,5 anos ( $D P=5,6)$, variando de 7 meses a 18 anos. Vale ressaltar que os tempos de serviço no Órgão e a idade dos respondentes não tiveram correlação.

A maioria dos participantes (72,73\%) nunca participou de treinamento anterior na área de governança, assim como permaneceu representativo o percentual $(63,64 \%)$ dos que nunca tiveram experiência prática na área. Por fim, quanto à participação em alguma ação efetiva do Órgão, 83,34\% afirmaram não ter esta experiência, o que indica que alguns já tiveram experiências em outras instituições devido à diferença dos percentuais. De todos os respondentes, apenas três indicaram ter participado de treinamento sobre o tema e terem experiências anteriores, mais especificamente na própria Secretaria, sendo que apenas um deles com tempo de serviço na organização abaixo da média de 9,45 anos. Esse é um indicativo da necessidade de investimento na Organização quanto às ações que permitam o conhecimento sobre o tema para o entendimento, seja por formação ou participando de alguma ação. O próprio entendimento se faz necessário para compreenderem que, de certa forma, todos os servidores públicos contribuem para a governança, devido à necessidade de adotarem os seus princípios (INTERNATIONAL FEDERATION OF ACCOUNTANTS, 2014; INSTITUTO BRASILEIRO DE GOVERNANÇA CORPORATIVA, 2015). 
PERCEPÇÕES DE COMITÊS SOBRE A APLICAÇÃO DA GOVERNANÇA PÚBLICA FEDERAL Karoll Haussler Carneiro Ramos - Lana Montezano - Andressa Oliveira Pinheiro - Marcos da Costa Avelar

Sobre o conhecimento de ações realizadas de governança na organização, em consonância com as respostas do tema anterior, a maioria dos respondentes não tem conhecimento de ações (59,09\%). Além dos três respondentes que afirmaram já terem participado de ação efetiva, apenas mais cinco possuem conhecimento, porém não participaram. Um participante, embora tenha respondido "não conhecer ações do local", relatou que já ouviu menções de governança na área de TI. Ressalta-se que um participante preferiu não responder às questões sobre conhecimentos prévios, deixando-as em branco. Os respondentes que destacaram ações de governança, destacaram ações relacionadas à estrutura, processos, capacitação, estratégia e riscos (Quadro 1). Não foram mencionadas ações relacionadas à medição e ao monitoramento, aquelas voltadas para prover transparência ao cidadão, apesar de existirem no Órgão. As respostas coadunam com os resultados de Correio e de Oliveira Correio (2019), em que as práticas de governança pública ainda estão nos primeiros passos, tendo um longo caminho a trilhar nesse sentido.

Quadro 1 - Ações de Governança

\begin{tabular}{|l|l|c|l|}
\hline \multicolumn{1}{|c|}{ Categoria } & \multicolumn{1}{|c|}{ Descrição } & $\begin{array}{c}\text { QTDE de } \\
\text { Relatos }\end{array}$ & \multicolumn{1}{|c|}{ Referência } \\
\hline $\begin{array}{l}\text { Estrutura de } \\
\text { governança }\end{array}$ & $\begin{array}{l}\text { Criação de comitês de gestão em temas diversos e áreas } \\
\text { de suporte a governança }\end{array}$ & 4 & $\begin{array}{l}\text { IBGC (2015); } \\
\text { OCDE (2004) }\end{array}$ \\
\hline $\begin{array}{l}\text { Governança de } \\
\text { gestão de processo }\end{array}$ & $\begin{array}{l}\text { Definição de diretrizes, monitoramento e controle de } \\
\text { gestão de processo }\end{array}$ & 1 & $\begin{array}{l}\text { Piemonte } \\
(2010) ; \\
\text { Brasil (2014) }\end{array}$ \\
\hline $\begin{array}{l}\text { Capacitação } \\
\text { formação gerencial para diferentes níveis hierárquicos } \\
\text { ger meio de cursos em planejamento estratégico e }\end{array}$ & 2 & Ramos (2015) \\
\hline $\begin{array}{l}\text { Desenvolvimento } \\
\text { de fóruns }\end{array}$ & $\begin{array}{l}\text { Fóruns de discussão para desenvolvimento do } \\
\text { planejamento estratégico e da melhoria do processo } \\
\text { finalístico da Organização }\end{array}$ & 4 & $\begin{array}{l}\text { Marques } \\
\text { (2007); Matias- } \\
\text { Pereira (2009) }\end{array}$ \\
\hline Gestão de riscos & $\begin{array}{l}\text { Mapeamento de riscos e elaboração de plano de } \\
\text { tratamento }\end{array}$ & $\begin{array}{l}\text { Marques } \\
(2007) ; \text { Matias- } \\
\text { Pereira (2009) }\end{array}$ \\
\hline
\end{tabular}

Fonte: Elaborado pelos autores a partir dos dados da pesquisa (2020).

Faz-se importante destacar o alto índice de desconhecimento sobre o tema e sobre ações de Governança na Organização, apesar da divulgação do Referencial Básico de Governança do TCU (BRASIL, 2014) e da necessidade de cumprimento do Decreto $\mathrm{n}$. $9.203 / 2017$. 
PERCEPÇÕES DE COMITÊS SOBRE A APLICAÇÃO DA GOVERNANÇA PÚBLICA FEDERAL Karoll Haussler Carneiro Ramos - Lana Montezano - Andressa Oliveira Pinheiro - Marcos da Costa Avelar

Quanto à definição de Governança, conforme exposto na metodologia, inicialmente foi elaborada a nuvem de palavras, a qual é apresentada na Figura 1, para permitir uma compreensão geral a respeito do entendimento de 21 participantes da pesquisa sobre Governança, pois um indicou não saber descrever uma definição. A análise preliminar indica que deixaram claro o contexto da administração pública, o envolvimento dos "donos do negócio" (proprietário, administrador, gestor, sociedade), e que o mesmo se refere a um conjunto, mecanismo ou estrutura para direcionar resultados.

Figura 1 - Nuvem de palavras das definições de Governança com IRAMUTEQ

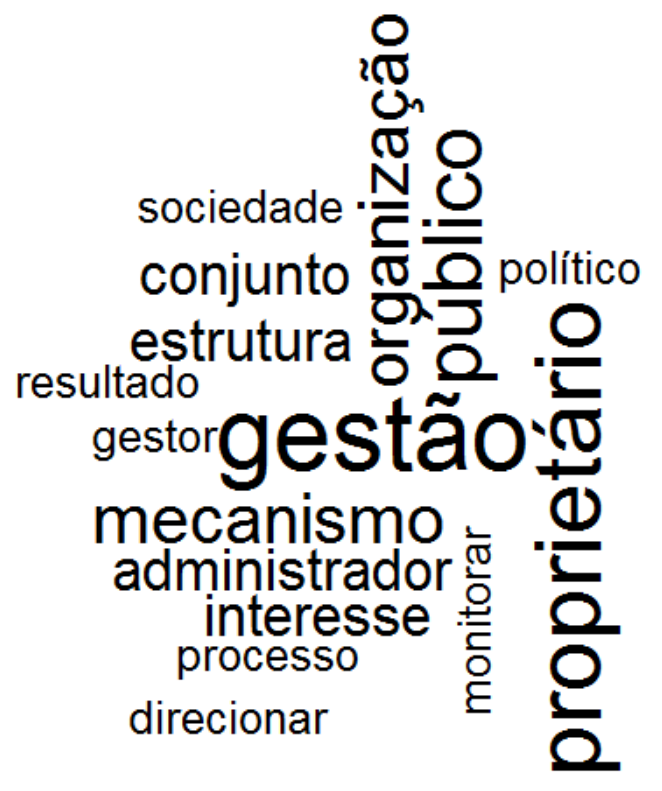

Fonte: Elaborado pelos autores com dados da pesquisa (2020).

Ao realizar uma análise de conteúdo, aplicando a triangulação para sua análise, foi possível desenvolver o agrupamento dos termos principais nas categorias apresentadas no Quadro 2. Dentre os 21 que responderam, os núcleos de sentido comuns identificados foram: gestão organizacional (20 ocorrências); mediação de interesses (13 ocorrências); metodologias de governança (7 ocorrências); direcionamento estratégico (6 ocorrências); estrutura de governança (6 ocorrências); alcance de resultados (5 ocorrências); monitoramento e controle (5 ocorrências); proteção ao negócio (4 ocorrências); princípios de governança (3 ocorrências); liderança e gestão de pessoas (3 ocorrências); gestão de processos (3 ocorrências); regulamentação e padrões (2 ocorrências); estratégia (2 ocorrências); e riscos (1 ocorrência). Verifica-se que todos os termos vão ao encontro das variáveis relevantes na literatura sobre governança e desempenho de Castelo et al. (2017). Revista Eletrônica de Estratégia \& Negócios, Florianópolis, v.14, n. 1, jan./abr. 2021. 
PERCEPÇÕES DE COMITÊS SOBRE A APLICAÇÃO DA GOVERNANÇA PÚBLICA FEDERAL Karoll Haussler Carneiro Ramos - Lana Montezano - Andressa Oliveira Pinheiro - Marcos da Costa Avelar

Apesar do conhecimento demonstrado sobre governança, os respondentes não souberam fazer a associação plena entre governança e as ações implementadas pela Secretaria.

Quadro 2 - Termos utilizados para definição de governança, por categoria

\begin{tabular}{|l|l|}
\hline \multicolumn{1}{|c|}{ Categoria } & \multicolumn{1}{|c|}{ Termos relacionados } \\
\hline Gestão organizacional & $\begin{array}{l}\text { Instrumento de gestão; capacidade de gestão; instância de gestão (de poder e } \\
\text { autoridade); boa gestão; planejamento; apoio à decisão; criar condições dentro } \\
\text { da organização }\end{array}$ \\
\hline Regulamentação e padrões & Políticas públicas; legislações, políticas e regras \\
\hline Gestão de processos & $\begin{array}{l}\text { Processos, procedimentos e atividades; melhoram processos e produtos e } \\
\text { atendem, da melhor maneira possível, seus clientes; ação integrada }\end{array}$ \\
\hline Estrutura de governança & Estrutura; instância de gestão (exercício de poder e autoridade) \\
\hline Mediação de interesses & $\begin{array}{l}\text { Mediação de interesses; mediação de conflitos; mediação de conflitos de } \\
\text { interesse entre administradores e proprietários, buscando solução dilema } \\
\text { principal-agente; mediação de funções; mediação de relações; foco no interesse } \\
\text { do proprietário; atender demandas da sociedade; projetos }\end{array}$ \\
\hline Proteção ao negócio & Proteção ao negócio \\
\hline Estratégia & Estratégia; mecanismo de estratégia \\
\hline Alcançar resultados & Alcançar ou atingir resultados estratégicos, resultados e objetivos \\
\hline Direcionamento estratégico & Direcionar; direcionamento estratégico; direção; orientar \\
\hline Metodologias de governança & $\begin{array}{l}\text { Framework; conjunto de instrumentos; arcabouço; conjunto de práticas } \\
\text { corporativas; práticas; mecanismos; método }\end{array}$ \\
\hline Princípios de governança & Prestação de contas; transparência \\
\hline $\begin{array}{l}\text { Liderança e gestão de } \\
\text { pessoas }\end{array}$ & Liderança; mecanismos de liderança; pessoas \\
\hline Riscos & Riscos \\
\hline Monitoramento e controle & Monitoramento de objetivos e controle; avaliar; avaliação \\
\hline Fonte: Elaborado pelos autores com
\end{tabular}

Fonte: Elaborado pelos autores com dados da pesquisa (2020).

Os principais resultados, "gestão organizacional" e "mediação de interesses" vão ao encontro da origem da Governança Corporativa, delineada a partir dos conflitos existentes na Teoria da Agência (EISENHARDT, 2015). Os apontamentos que a relacionam com "estratégia" estão condizentes com a definição adotada pela OECD (2004). É interessante destacar que não houve abordagens que fizessem ligação entre governança e tecnologia da informação - não se sabe se tal fenômeno ocorreu por desconhecimento dos respondentes, ou pela possibilidade de eles diferenciarem Governança Corporativa da Governança de TI. De forma geral, pode-se dizer que os termos utilizados estão ainda consonantes com a definição do Decreto n. 9.203/2017, o qual trata de Governança Pública - o que era esperado, afinal, os respondentes são todos servidores de uma Secretaria da Administração Direta do Governo Federal. 


\subsection{DIFICULDADES E POSSÍVEIS GANHOS COM A GOVERNANÇA PÚBLICA}

Em relação às dificuldades para implantação da Governança Pública no Órgão pesquisado, após o alinhamento conceitual sobre a temática, 15 participantes apresentaram relatos a respeito das suas percepções, cinco não responderam à questão, e dois afirmaram não saber quais são as principais dificuldades. Os que responderam indicaram 27 relatos, e a partir da triangulação desenvolvida pelos pesquisadores, permitiu o agrupamento das informações em seis categorias temáticas, sendo elas, em ordem de maior ocorrência de relatos: limitações em governança; aspectos culturais do serviço público; limitações em processos de comunicação; pouco patrocínio; baixo comprometimento e interesse dos envolvidos; influências externas. A partir dos relatos foi possível estabelecer as categorias e as definições constitutivas que descrevem ao que se refere cada categoria, as quais podem ser visualizadas no Quadro 3, juntamente com o quantitativo do total de relatos que foram agrupados por núcleos de sentido, e exemplos de relatos coletados para ilustração dos dados brutos.

Quadro 3 - Dificuldades de implementação de Governança

\begin{tabular}{|c|c|c|c|}
\hline Categoria & Definição constitutiva & $\begin{array}{c}\text { QTDE } \\
\text { de } \\
\text { Relatos }\end{array}$ & Exemplos de relatos \\
\hline $\begin{array}{l}\text { Limitações em } \\
\text { governança }\end{array}$ & $\begin{array}{l}\text { Refere-se a limitações na institucionalização da } \\
\text { estrutura de governança na organização, bem } \\
\text { como no estabelecimento de condições à sua } \\
\text { efetiva implantação (ex.: normativos, } \\
\text { capacitação, estratégia). }\end{array}$ & 9 & $\begin{array}{l}\text { - "Falta de um comitê central” } \\
\text { - “Prazo de implementação". }\end{array}$ \\
\hline $\begin{array}{l}\text { Aspectos } \\
\text { culturais do } \\
\text { serviço público }\end{array}$ & $\begin{array}{l}\text { Refere-se a aspectos culturais limitadores a } \\
\text { mudanças organizacionais referentes à adoção } \\
\text { de novos modelos de gestão na administração } \\
\text { pública que são adotados na iniciativa privada, } \\
\text { bem como aspectos de características inerentes } \\
\text { ao serviço público (como a burocracia). }\end{array}$ & 6 & $\begin{array}{l}\text { - "Dificuldade de } \\
\text { implementação de técnicas do } \\
\text { setor privado na administração } \\
\text { pública." } \\
\text { - "Dificuldade de mudanças nos } \\
\text { estilos de administração dentro } \\
\text { do Órgão". }\end{array}$ \\
\hline $\begin{array}{l}\text { Limitações em } \\
\text { processos de } \\
\text { comunicação }\end{array}$ & $\begin{array}{l}\text { Refere-se à falta de estratégias de divulgação } \\
\text { das informações que permitam a transparência } \\
\text { das informações, bem como de estruturação } \\
\text { adequada do processo para maior } \\
\text { confiabilidade das informações. }\end{array}$ & 4 & $\begin{array}{l}\text { - "Assimetria de informação." } \\
\text { - "Conhecimentos } \\
\text { desalinhados." }\end{array}$ \\
\hline $\begin{array}{l}\text { Pouco } \\
\text { patrocínio }\end{array}$ & $\begin{array}{l}\text { Refere-se à percepção da necessidade de maior } \\
\text { apoio da alta administração para efetiva } \\
\text { implantação da governa na organização. }\end{array}$ & 3 & $\begin{array}{l}\text { - "Falta de interesse da alta } \\
\text { administração." }\end{array}$ \\
\hline
\end{tabular}




\begin{tabular}{|l|l|c|l|}
\hline \multicolumn{1}{|c|}{ Categoria } & \multicolumn{1}{|c|}{ Definição constitutiva } & $\begin{array}{c}\text { QTDE } \\
\text { de } \\
\text { Relatos }\end{array}$ & \multicolumn{1}{|c|}{ Exemplos de relatos } \\
\hline $\begin{array}{l}\text { Baixo } \\
\text { comprometime } \\
\text { nto e interesse } \\
\text { dos envolvidos }\end{array}$ & $\begin{array}{l}\text { Refere-se à falta de envolvimento dos } \\
\text { servidores em participar de ações relacionadas à } \\
\text { implantação da governança, bem como em se } \\
\text { engajar na mudança ao novo modelo de gestão. }\end{array}$ & 3 & $\begin{array}{l}\text { - "Falta de engajamento das } \\
\text { pessoas (servidores)." }\end{array}$ \\
\hline $\begin{array}{l}\text { Influências } \\
\text { externas }\end{array}$ & $\begin{array}{l}\text { Refere-se a tentativas de agentes externos } \\
\text { influenciarem em decisões da organização. }\end{array}$ & 2 & $\begin{array}{l}\text { - "Influências principalmente } \\
\text { políticas." }\end{array}$ \\
\hline
\end{tabular}

Fonte: Elaborado pelos autores a partir dos dados da pesquisa (2020).

A dificuldade recorrente está relacionada a "limitações em governança", o que remete à necessidade de a Organização se estruturar de forma adequada para adoção da governança pública, em conformidade com a legislação vigente. A segunda mais recorrente diz respeito a aspectos culturais do serviço público que limitam a adoção de modelos de gestão de iniciativa privada para a pública, sem uma adequada adaptação do modelo ao contexto público, considerando os valores e práticas organizacionais, alinhado ao que foi apontado por Benedicto et al. (2013) quanto à dificuldade de incorporar princípios da governança corporativa para administração pública devido às práticas da sua cultura organizacional.

De um modo geral, a partir da análise dos dados levantados sobre as dificuldades, percebe-se que a maior parte dos problemas de implementação de governança ocorrem pela mesma razão que motivaram a sua existência: conflitos de interesse e assimetria de informação e decisão entre agentes (nesse caso, os servidores) e principais (gestores e alta administração). Os conflitos de interesse são demonstrados pelo baixo comprometimento e interesse dos envolvidos, bem como pelos aspectos culturais do serviço público e limitações em processos de comunicação. O fato de alguns respondentes terem destacado "assimilação incipiente do conceito de accountability por parte dos gestores, associado à falta de conhecimento de ações de governança efetuadas no Órgão, demonstram fragilidade na sua aplicação. Essas dificuldades, contudo, podem ser dirimidas - o próprio Referencial Básico de Governança do TCU (2020) já aponta práticas de governança relativas à liderança, estratégia e controle.

Por fim, 19 servidores apresentaram 30 relatos relativos a possíveis ganhos quanto à implantação da Governança na Instituição que trabalham. Além disso, dois participantes da pesquisa não indicaram possíveis ganhos, e um registrou que acredita ser possível implantar 
PERCEPÇÕES DE COMITÊS SOBRE A APLICAÇÃO DA GOVERNANÇA PÚBLICA FEDERAL Karoll Haussler Carneiro Ramos - Lana Montezano - Andressa Oliveira Pinheiro - Marcos da Costa Avelar

ações de governança na Organização. A consolidação da análise dos dados gerou cinco categorias, sendo elas: (1) melhorias na gestão, (2) melhorias no alcance de resultados, (3) melhorias na gestão de processos, (4) melhorias na gestão de riscos, e (5) maior transparência. Optou-se por diferenciar as categorias de melhoria na gestão de processos e melhoria na gestão de riscos da categoria de melhorias na gestão, em função do núcleo de sentido serem mais específicos e permitir a identificação da percepção do quanto a governança pode contribuir com estes modelos de gestão. O Quadro 4 apresenta as categorias, com suas definições, quantidade de relatos de originaram o estabelecimento da respectiva categoria e um exemplo ilustrativo de relato. Os benefícios apresentados corroboram para resolver os principais problemas levantados pelos próprios respondentes.

Quadro 4 - Possíveis ganhos com a implementação de Governança

\begin{tabular}{|c|c|c|c|}
\hline Categoria & Definição constitutiva & $\begin{array}{l}\text { QTDE de } \\
\text { relatos }\end{array}$ & Exemplos de relatos \\
\hline $\begin{array}{l}\text { Melhorias na } \\
\text { gestão }\end{array}$ & $\begin{array}{l}\text { Refere-se à oportunidade de } \\
\text { aperfeiçoamentos na gestão da } \\
\text { organização, com vistas a } \\
\text { proporcionar melhoria no processo } \\
\text { decisório. }\end{array}$ & 11 & $\begin{array}{l}\text { - "Melhoria na qualidade do } \\
\text { gasto público." } \\
\text { _ "Maior clareza na definição de } \\
\text { prioridades." }\end{array}$ \\
\hline $\begin{array}{l}\text { Melhorias no } \\
\text { alcance de } \\
\text { resultados }\end{array}$ & $\begin{array}{l}\text { Refere-se à possibilidade de gerar } \\
\text { melhores serviços e resultados } \\
\text { para sociedade }\end{array}$ & 6 & $\begin{array}{l}\text { - "Melhorar as entregas da } \\
\text { organização à sociedade." }\end{array}$ \\
\hline $\begin{array}{l}\text { Melhorias na } \\
\text { gestão de } \\
\text { processos }\end{array}$ & $\begin{array}{l}\text { Refere-se à possibilidade de } \\
\text { aperfeiçoamento dos processos } \\
\text { organizacionais. }\end{array}$ & 5 & $\begin{array}{l}\text { - "Maior organização nos } \\
\text { processos de trabalho e de } \\
\text { decisão." }\end{array}$ \\
\hline $\begin{array}{l}\text { Melhorias na } \\
\text { gestão de riscos }\end{array}$ & $\begin{array}{l}\text { Refere-se aos benefícios } \\
\text { provenientes de identificação, } \\
\text { tratamento e prevenção de riscos } \\
\text { dos processos. }\end{array}$ & 4 & $\begin{array}{c}\text { - "Mapeamento e prevenção } \\
\text { riscos." }\end{array}$ \\
\hline $\begin{array}{l}\text { Maior } \\
\text { transparência }\end{array}$ & $\begin{array}{l}\text { Refere-se a proporcionar condições } \\
\text { para melhorar transparência das } \\
\text { informações. }\end{array}$ & 4 & $\begin{array}{l}\text { "Aprimorar os mecanismos de } \\
\text { transparência e compliance" }\end{array}$ \\
\hline
\end{tabular}

Fonte: Elaborado pelos autores a partir dos dados da pesquisa (2020).

O Quadro 4 revela que a maioria dos respondentes acredita que a governança pode trazer melhorias na gestão, em termos de propiciar a melhoria do processo decisório. $\mathrm{Na}$ contramão, os temas que foram menos associados à governança seriam "melhoria na gestão de riscos" e "maior transparência". Esse posicionamento serve de ponto de alerta para maior aprofundamento do tema na Organização. 
PERCEPÇÕES DE COMITÊS SOBRE A APLICAÇÃO DA GOVERNANÇA PÚBLICA FEDERAL Karoll Haussler Carneiro Ramos - Lana Montezano - Andressa Oliveira Pinheiro - Marcos da Costa Avelar

\section{CONCLUSÕES}

O presente artigo teve por finalidade compreender a Governança corporativa a partir da visão de 22 servidores de uma Secretaria do Poder Executivo do Governo Federal, todos ocupantes de mesmo cargo de nível superior e que compõem os comitês de apoio interno à governança. Nesse sentido, buscou-se apreender informações sobre seus conhecimentos em nível de conceito, principais dificuldades e possíveis ganhos ao implementar ações desse escopo no respectivo órgão. Com isso, este artigo traz uma contribuição acadêmica no sentido de apresentar a perspectiva dos servidores sob a adoção da Governança pública brasileira, devido à escassez de publicações científicas nacionais. Essa ótica se faz relevante devido ao fato de os servidores também serem atores importantes para implantação da governança, uma vez que são os agentes que aplicam as normas e têm o seu papel na garantia do cumprimento dos princípios da governança.

Em relação ao conceito de Governança Corporativa Pública, foi possível denotar que, de forma geral, os respondentes utilizam termos que vão ao encontro do que é designado pelo Decreto n. 9.203, de 22 de novembro de 2017. As terminologias mais utilizadas para descrever Governança foram relativas a framework, instrumento, práticas, mecanismos; embora a categoria que obteve destaque na formação do conceito tenha sido a "gestão organizacional", seguida de "mediação de interesses". Apesar das estruturas de governança pública estarem se definindo, muitas vezes devido às orientações dos Órgãos de Controle Interno e Externo, as ações governança não são perceptíveis aos olhos dos servidores, precisando avançar nesse sentido.

Quanto às principais dificuldades abordadas, constata-se a falta de monitoramento e controle das atividades que deveriam ser executadas. Por outro lado, os respondentes acreditam que a implementação de governança é capaz de reverter esse quadro, e inclusive melhorar outros aspectos tais como a comunicação interna, os processos executados e a própria tomada de decisão.

Destaca-se como limitações da pesquisa a abordagem qualitativa e amostra, que não permitem a generalização dos resultados, tanto sob a perspectiva de ter sido em uma única organização quanto a técnica de amostragem não probabilística e o tamanho da amostra. 
PERCEPÇÕES DE COMITÊS SOBRE A APLICAÇÃO DA GOVERNANÇA PÚBLICA FEDERAL Karoll Haussler Carneiro Ramos - Lana Montezano - Andressa Oliveira Pinheiro - Marcos da Costa Avelar

Outra limitação diz respeito ao risco de os participantes terem complementado alguma resposta de perguntas que deveriam ter sido respondidas antes da apresentação de alinhamento ou mesmo que tenham preferido responder todo o questionário após a apresentação, o que pode gerar viés de resposta com base nos conteúdos aprendidos. Isso, contudo, não invalida os achados nesta pesquisa, uma vez que a problemática, "como servidores públicos federais do Brasil entendem a Governança", foi respondida, além do fato de ser um estudo que não foi realizado antes, permitindo a exploração do campo para contribuir com futuras pesquisas.

Nesse sentido, como agenda para pesquisas futuras, sugere-se o levantamento de aspectos de dificuldades de implementação e possíveis ganhos em outros órgãos públicos, com uma maior e mais diferenciada amostragem para continuidade na exploração desses fatores no contexto público, bem como realizar estudos longitudinais que permitam o acompanhamento da ocorrência destes fatores. Recomenda-se também a identificação de modelos de governança pública e das ações que estão sendo efetivamente adotadas, bem como dos resultados obtidos com as práticas de governança na administração pública, por meio de diferentes fontes de dados (primários ou secundários, e perspectivas de diferentes atores envolvidos).

\section{REFERÊNCIAS}

BARDIN, L. Análise de conteúdo. 70. ed. São Paulo: Edições 70, 2011. 229p.

BARRETT, Pat. New development: Financial reform and good governance. Public Money \& Management, v. 34, n. 1, p. 59-66, 2014.

BEERI, Itai; USTER, Anna; VIGODA-GADOT, Eran. Does Performance Management Relate to Good Governance? A Study of Its Relationship with Citizens' Satisfaction with and Trust in Israeli Local Government. Public Performance \& Management Review, p. 1-39, 2018.

BENEDICTO, S. C.; GUIMARÃES JÚNIOR, E. S.; PEREIRA, J. R.; ANDRADE, G. H. N. Governança corporativa: uma análise da aplicabilidade dos seus conceitos na administração pública.

Organizações Rurais \& Agroindustriais. v. 15, n. 2, p. 286-300, 2013.

BESSA, L. F. M. Aspectos Conceituais da Governança e o Uso das Mídias Sociais. VI Congresso CONSAD de Gestão Pública. Painel 23/087 - Experiências recentes em governo eletrônico e transparência: conceitos, desafios e práticas. Brasília, DF, 2013. 
PERCEPÇÕES DE COMITÊS SOBRE A APLICAÇÃO DA GOVERNANÇA PÚBLICA FEDERAL Karoll Haussler Carneiro Ramos - Lana Montezano - Andressa Oliveira Pinheiro - Marcos da Costa Avelar

BRANCO, Cláudio Souza Castello; DA CRUZ, Cláudio Silva. A prática de governança corporativa no setor público federal. Revista do TCU, n. 127, p. 20-27, 2013.

BRASIL. Decreto no 9.203 de 22 de novembro de 2017. Dispõe sobre a política de governança da administração pública federal direta, autárquica e fundacional. 2017.

BRASIL. Tribunal de Contas da União. Referencial Básico de Governança Aplicável a Órgãos e Entidades da Administração Pública e Ações Indutoras de Melhoria. 2ạ versão. Brasília, 2014.

BRASIL. Tribunal de Contas da União. Referencial básico de governança aplicável a organizações públicas e outros entes jurisdicionados ao TCU / Tribunal de Contas da União. Edição 3 - Brasília: TCU, Secretaria de Controle Externo da Administração do Estado - Secex Administração, 2020.

BROCCO, Camila; GRANDO, Tadeu; MARTINS, Vanessa De Quadros; JÚNIOR, Antônio Carlos Brunozi; CORRÊA, Suelen. Transparência da gestão pública municipal: Fatores explicativos do nível de transparência dos municípios de médio e grande porte do rio grande do sul. Revista Ambiente Contábil, v. 10, n. 1, p. 139-159, 2018.

BROILO, P. L.; SILVA, R. G. C.; FRIO, R. S.; OLEA, P. M.; NODARI, C. H. Abordagens Mistas na Pesquisa em Administração: uma análise bibliométrica do uso de multimétodos no Brasil. Administração: Ensino e Pesquisa, v. 16, n. 1, p. 9-39, 2015.

BUTA, B. O.; TEIXEIRA, M. A. C. Governança pública em três dimensões: conceitual, mensural e democrática. Organizações \& Sociedade, v. 27, n. 94, p. 370-395, 2020.

CAMPANÁRIO, M. A.; MURITIBA, S. N.; MURITIBA, P. M.; RIBEIRO, H. C. M. Governança Corporativa em empresas públicas. RACE, v. 13, n. 2, p. 689-718, 2014.

DE GOUVÊA, D. G. T. de et al. Governança Corporativa e Compliance no Setor Público: análise da experiência da Eletrobras à luz da lei das empresas estatais 13.303/2016. XLIV ENCONTRO DA ANPAD - EnANPAD 2020 Evento on-line, 2020.

LEITE CASTELO, S.; DUARTE CASTELO, A.; LEITE CASTELO, J.; SILVEIRA ARAÚJO, H.; FIRMINO DE ARAÚJO, V. Governança pública e performance: uma revisão sistemática de literatura. Revista Controle: Doutrinas e artigos, v. 15, n. 2, p. 289-319, 2017.

CORREIO, M. N. O. P.; DE OLIVEIRA CORREIO, O. Vieira. Práticas de Governança Pública Adotadas pela Administração Pública Federal Brasileira. Administração Pública e Gestão Social, v. 11, n. 2, 2019.

COSTA, A. C. P.; LEAL, A. F. P.; NASCIMENTO, L. C. B.; MENDONÇA, M. C.; GUERRA, L. C. B. Alinhamento da gestão de processos com os mecanismos do modelo de governança pública do TCU: o estudo de caso em uma universidade federal da Amazônia Oriental. Revista do Serviço Público, v. 69, n. 3, p. 741-772, 2018.

DANI, A. C.; MAGRO, C. B. D.; MATIAS-PEREIRA, J.; ZONATTO, V. C. S. Efeito da qualidade da governança pública sobre o sentimento de confiança da população nas instituições 
PERCEPÇÕES DE COMITÊS SOBRE A APLICAÇÃO DA GOVERNANÇA PÚBLICA FEDERAL Karoll Haussler Carneiro Ramos - Lana Montezano - Andressa Oliveira Pinheiro - Marcos da Costa Avelar

governamentais: uma análise para países latino-americanos. Administração Pública e Gestão Social, v. 10, n. 4, p. 228-238, 2018.

DUARTE, E.; CARDOZO, M. A.; VICENTE, E. F. R. Governança: Uma Investigação da Produção Científica Brasileira no Período de 2000 a 2009. Contabilidade, Gestão e Governança, v. 15, n. 1, p. 115-127, 2012.

EISENHARDT, K. M. Teoria da Agência: Uma Avaliação e Revisão. Revista de Governança Corporativa, v. 2, n. 1, p. 1-36, 2015.

FLÓREZ, J. El gobierno corporativo en el ámbito del sector público: un estudio bibliométrico en las revistas ubicadas en el área de Administración Pública. Revista Facultad de Ciencias Económicas: Investigación y Reflexión, v. 25, n. 1, p. 161-175, 2017.

FONTES FILHO, J. R. Governança Organizacional Aplicada ao Setor Público. VIII Congreso Internacional del CLAD sobre la Reforma del Estado y de la Administración Pública. Panamá, 2003.

GRAAF, G.; PAANAKKER, H. Good governance: Performance values and procedural values in conflict. The American Review of Public Administration, v. 45, n. 6, p. 635-652, 2015.

INSTITUTO BRASILEIRA DE GOVERNANÇA CORPORATIVA. IBGC. Código das melhores práticas de governança corporativa. 5. ed. São Paulo, SP: IBGC, 2015.

INTERNATIONAL FEDERATION OF ACCOUNTANTS (IFAC); THE CHARTERED INSTITUTE OF PUBLIC FINANCE AND ACCOUNTANCY (CIPFA). International Framework: Good Governance in the Public Sector. New York: IFAC, 2014.

KOVAČ, P; TOMAŽEVIČ, N.; LEBEN, A; ARISTOVNIK. Reforming public administration in Slovenia: between theory and practice of good governance and good administration. International Journal of Public Policy, v. 12, n. 3-6, p. 130-148, 2016.

MAGALHÃES, B. D.; COELHO, F. S. Imbricações entre governança pública e a governabilidade para a implementação da reforma administrativa: o caso da gestão para a cidadania em Minas Gerais (2011-2014). Revista Gestão e Planejamento, v.19, p. 350-366, 2018.

MARQUES, M. C. C. Aplicação dos Princípios da Governança Corporativa ao Sector Público. Revista de Administração Contemporânea, v. 11, n. 2, p. 11-26, 2007.

MATIAS-PEREIRA, J. Curso de Administração Pública: foco nas instituições e ações governamentais. 3. ed. São Paulo: Atlas, 2010.

MOLINARO, L. F. R.; RAMOS, K. H. C. Gestão de Tecnologia Da Informação, Governança de TI: Arquitetura E Alinhamento Entre Sistemas de Informação EO Negócio. Grupo Gen-LTC, 2011.

OECD. Organisation for Economic Co-Operation and Development. Principles of Corporate Governance, 2004. Disponível em: http://www.oecd.org. 
PERCEPÇÕES DE COMITÊS SOBRE A APLICAÇÃO DA GOVERNANÇA PÚBLICA FEDERAL Karoll Haussler Carneiro Ramos - Lana Montezano - Andressa Oliveira Pinheiro - Marcos da Costa Avelar

PEIXE, B. C. S.; ROSA FILHO, C. da; PASSOS, G. de. A. Governança pública e accountability: Uma análise bibliométrica das publicações científicas nacionais e internacionais. Revista Contemporânea de Contabilidade, v. 15, n. 36, p. 77-96, 2018. Disponível em: https://periodicos.ufsc.br/index.php/contabilidade/article/view/2175-8069.2018v15n36p77

PIEMONTE, L. A. Gestão para Inovar: como integrar a gestão convencional, orientada ao desempenho, com os novos requisitos de inovação e foco no cliente. São Paulo: Portal Editora. 318p., 2010.

PROCOPIUCK, M. Políticas públicas e fundamentos da administração pública: análise e avaliação, governança e redes de políticas, administração judiciária. Editora Atlas, 2013.

RAMOS, K. H. C. Análise Multivariada de Fatores Críticos de Sucesso em Governança de TI na Administração Pública Federal à Luz dos Dados de Controle Externo. Tese (Doutorado em Engenharia). Universidade de Brasília. Departamento de Engenharia Elétrica, Brasília. 229f. 2015.

ZAPPELLINI, M. B.; FEUERSCHÜTTE, S. G. O Uso da Triangulação na Pesquisa Científica Brasileira em Administração. Administração: Ensino e Pesquisa, v. 16, n. 2, p. 241-273, 2015.

WATERMAN, R. Authority Migration and Accountability in Canadian Public Governance. Canadian Journal of Political Science/Revue canadienne de science politique, v. 47, n. 2, p. 215-235, 2014.

WEBER, G. E.; SANTOS, S. R. T. dos. Governança corporativa no setor público: um estudo aplicado à Companhia Riograndense de Saneamento. Revista Eletrônica do Curso de Ciências Contábeis, v. 9, n. 1, p. 272-300, 2020. 